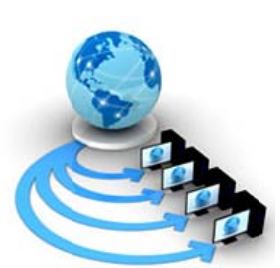

Volume 9, No. 1, January-February 2018

International Journal of Advanced Research in Computer Science

RESEARCH PAPER

\author{
Available Online at www.ijarcs.info
}

\title{
DEVELOPMENT OF AN EXCLUSIVE WEB APPLICATION FOR FAMILY
}

\author{
Ravishankar H N \\ CSE,GAT \\ Bangalore,India
}

\author{
Rohith R \\ CSE,GAT \\ Bangalore,India
}

\author{
Snigdha Sen \\ CSE,GAT \\ Bangalore,India
}

\author{
Pawan V \\ CSE,GAT \\ Bangalore,India
}

\author{
Naveen $\mathrm{M}$ \\ CSE,GAT \\ Bangalore,India
}

\begin{abstract}
The project deals with designing and implementing a platform for communication for family exclusively. The application should enable members of the family to post messages, share photos, maintain group calendars and address books, send group emails, view latest logins of all the other members and chat with any of the members who are online. If a user is connected with a social networking site, he/she might not feel lonely too.Developing a personal private family network might be a very good option to consider.This application will also help users to keep track of memorable family events, occasions. In this paper we tried to develop a social networking site exclusively for family.
\end{abstract}

Keywords: Family website; MySQL; PHP; Database

\section{INTRODUCTION}

Social networking site have gained much popularity in recent years because of the opportunities they give people to connect to each other in an easy manner and share various kinds of information. However these networking sites are designed based on a paradigm which limits the mobility of users. When a person has hundreds of friends or networks on Facebook or Twitter he/she can start feeling overcrowded. Status updates are missed and tweets are overlooked. By having a private family oriented social network this risk can be reduced. A person can easily share his/her personal message exclusively with family members. In emergency also a person can alert only his/her family members for help. Therefore a private family network was need of the hour. This application will help family members across globe to share their views, message their relative and even inform any important events.It also helps them to understand their family hierarchy.

\section{RELATED WORK}

Now a days social networking sites has huge impact on mass. They help to connect people with similar interest across the world.Several websites are beginning to tap into the power of the social networking model for philanthropy. Social networks are providing a different way for individuals to communicate digitally. In September 1999, Ancestry.com[1] reported 880 unique visitors. By comparison, in March 2007, the same site reported4.5 million unique visitors. Ancestry.com is the largest online family history site, with over 2 million subscribers.
SixDegrees.com [2] was the first social network launched in 1997.Users were able to create profile, list friends and even browse their friend list using this site. It also helps users to share messages among themselves.From 1997 to 2001AsianAvenue, Black Planet[3] and MiGente started their business by supporting users to create personal, professional profile.In 2004 Mark Zuckerberg along with Eduardo Saverin, Andrew McCollum, Dustin Moskovitz, and Chris Hughes launched facebook[4] website. The founders had initially limited the website's membership to Harvard students; however, later they expanded it to higher education institutions in the Boston area, the Ivy League schools, and Stanford University .Now it is a very popular networking site.

Another popular networking site LinkedIn[5] was founded on December 28, 2002 and launched on May 5, 2003.This site is basically for professionals sharing interests about their job. Next came twitter [6,7] which is online news and social networking service provider where messages are called as "tweets". Registered userscan post messages there but unregistered users can only read them. Google+ [8,9]was launched in June 2011.Google Plus (stylized as Google+) is an interest-based social network that is owned and operated by Google.

\section{PROPOSED SYSTEM}

Our Web application provides a platform [10] which is private enough and is exclusively built for family use.

The overview of the functionality [11] of the family web application is explained below:

- In the web application the person who registers first to the site becomes the admin and each time a new user 
registers to his family, the admin has to activate the new user account.

- $\quad$ Once the user account gets activated by the admin, the user gets added to the admin's family.

- $\quad$ The user may also update his profile with profile photo and basic information including disease history and blood group.

- Web application users can post messages, share photos, maintain group calendars, address books, send group emails and view latest logins of all the other members.

- Users can chat with any of the members who are online.

- Users can also create a family tree which helps him/her to understand his family hierarchy[12].

\section{SYSTEM ARCHITECTURE}

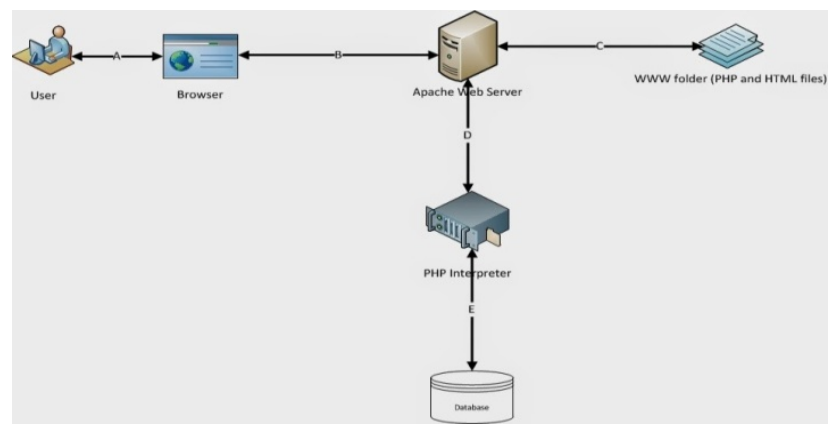

Fig. 1. System Architecture

Fig. 1. describes overall system architecture. The numbers used below beside the Label names following 1 for Request flow and 2 for response flow.

-A1: First user accessed the website through browser. That means user types the URL of the website in browser and hit go.

- B1:The page request on browser will reach to the Web Server (Apache).

-C: Web server[13] will collect that requested page (HTML or PHP or Image file etc.) from its document root.

-B2: Now if it is a static element like HTML,CSS, image file or Java Script file then Apache will send it directly to browser.

-A2: Browser will render it to user on screen.

-D1: If it is a PHP[14] file then Apache sends the content of the file to PHP Interpreter. PHP interpreter interprets the PHP code and executes it. If DB operation is required it performs the same (E).

-D2: PHP Interpreter generates output (if the PHP code is to generate any output) and sends to ApacheB2: Apache sends that content to browser.

-A2: Browser renders it to users' screen

All static components like HTML, CSS files, image Files, Java Scripts etc. doesn't need interpreter. Our web browsers are built to render them and display on screen properly. That is why if user requests for these kind of components Apache collects them from Document root and sends back to Browser directly. If requested page is a PHP page Apache will send it to PHP interpreter to get it translated and executed.

Listed static components reside on Server and are considered as a part of User Interface. As they get rendered at user's browser it is referred as Client side component. In web technology Browsers are Client terminals.PHP files act as server side components. These PHP files have dependencies on another server side component and hence PHP Interpreter cannot be executed only on browsers .PHP[15,16] files are kept on Server (in Document root). PHP Interpreter interprets PHP language and executes instructions as per code. It does not need compilation.

\section{MODULES OF THE PROJECT}

Following are different modules in this application[17].

- Login Module

- Registration Module

- Media Uploading Module

- Chat Module

- $\quad$ Profile Module

- Admin Module

Login Module: Login is for existing users, if they are new to the site they have to register by providing required data. Login process is as follows

- Enter username

- Enter password

- $\quad$ Click on Login Button

Username and Password authentication will be done. If authentication successful user home page is displayed

Registration Module: Registration module is for new users who are new to this site. They can become users of this site by registering to the website. Registration process is as follows

- Enter unique user name

- Enter password

- Enter First Name

- Enter Last Name

- Enter Email ID

During registrationprocess, entered email id is validated. Some of the conditions that are checked during validation are as follows: Email id should mandatorily contain '@' symbol. Email id should be containing a minimum of 10 characters and many such others. If all the entered details are found to be valid, then the user's account is successfully registered which needs to be activated by the administrator. Once the account is activated the user is allowed to login and can use the web application.

Media Uploading Module: The member clicks on the 'Photos' link and is taken to a page where there are thumbnail images of all the photos that have been uploaded thus far. Below the thumbnail image, the name of the person who uploaded the picture and the date that it was uploaded are displayed. Clicking on the thumbnail image takes the user to the full size image. The member can upload pictures by clicking on the 'Upload' link on the photos page. In the pop-up window, he may either type the name of the file with the path, or browse and select the file name. Once the picture is uploaded, it may be viewed by any member.

Chat Module: A list of members, who are currently logged on, is displayed in a column labeled as 'Online'. When a user logs on, his name is added to the list \& he can see which other Members of his family are currently viewing the page. He can then double click on them ember's name with whom he wants to start chatting. In the chat window, he can send and receive messages. 
Profile Module: Initially a profile is created with the data provided at the time of user registration and that can be edited and updated in the profile module. Profile module contains following options

- User can upload profile picture

- User can update basic information

- User can add Blood group and Disease details in profile details

- Users can fill their address/contact information in their profiles which can be accessed by his/her family members

Admin Module: For each family there must be an administrator who will be activating the user accounts coming under his family. The one who first registers to the family website will become the admin of his/her family. He would have all the privileges to accept new user registration. The admin may also wish to auto-activate accounts. Admin has all privileges of modifying the website by adding or removing plugins.Admin credentials should be used

\section{RESULTS}

The expected results are as follows:

An exclusive family networking site that offers its users a private network to stay connected with their family members. A tree structure displays the family hierarchy.

Some of the snapshots of the working web application are provided below:

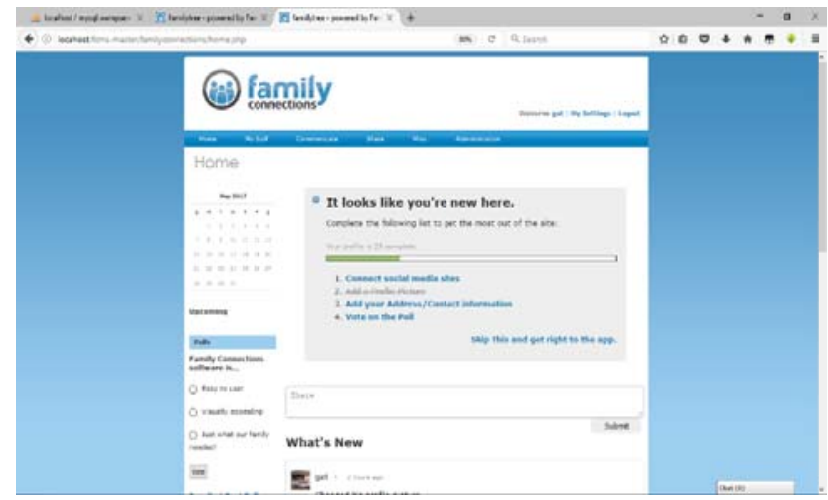

Snapshot1: First window after login

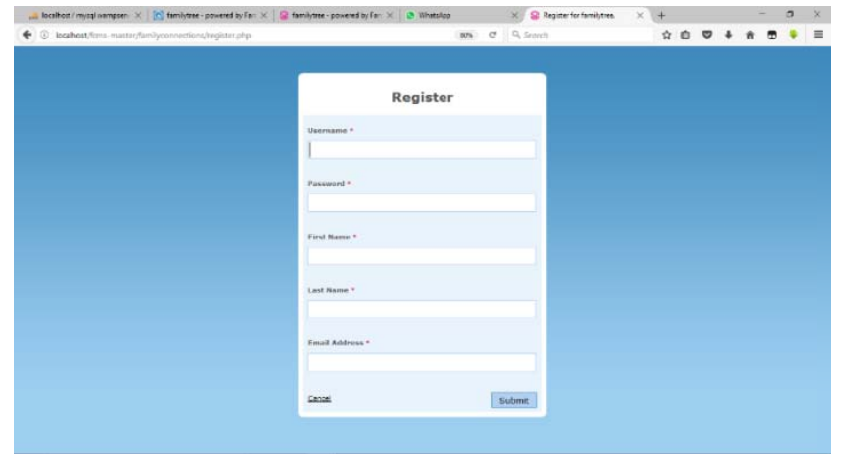

Snapshot 2: Member Registration Form

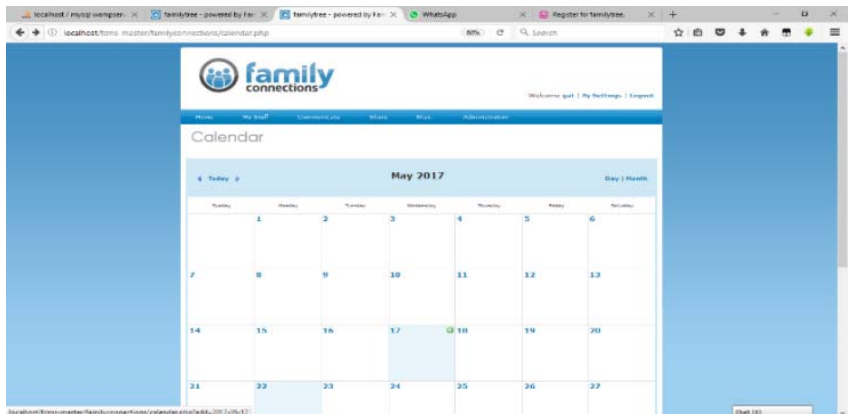

Snapshot 3: Adding calendar events

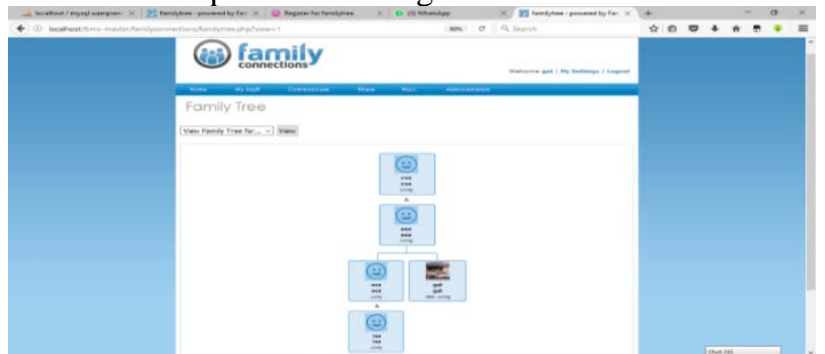

Snapshot 4: Family Hierarchy Layout

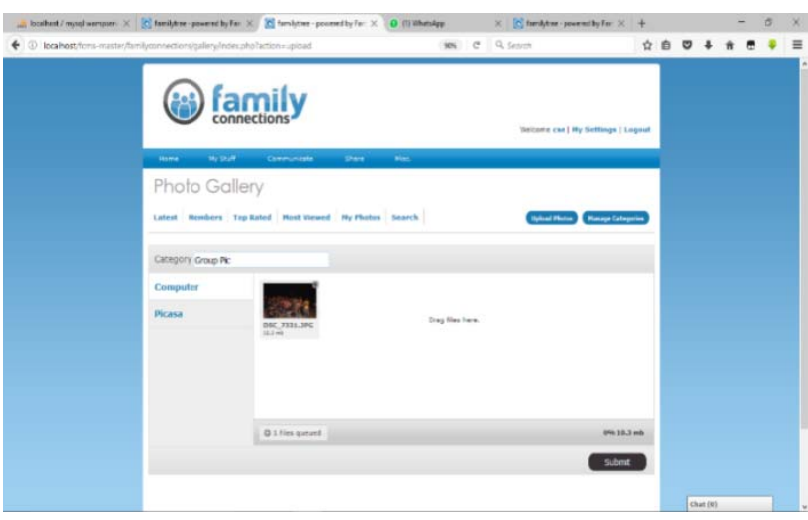

Snapshot 5: Adding Photos to Gallery

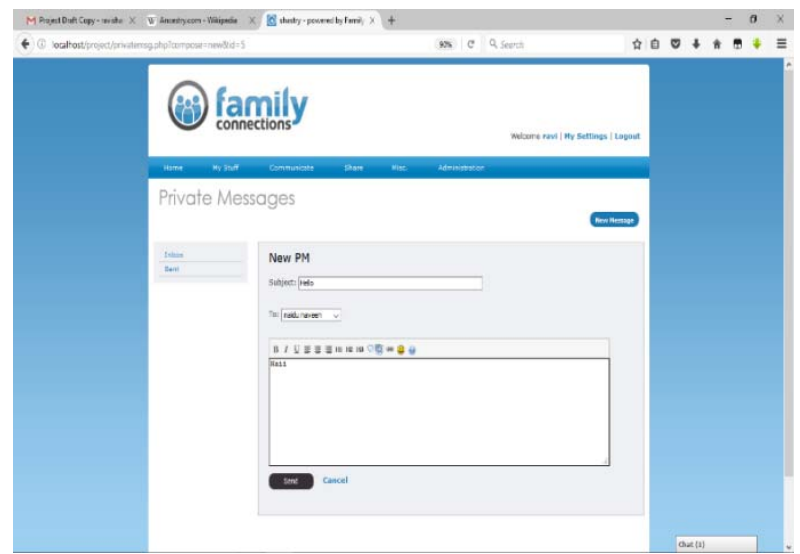

Snapshot 6: Sending Private Messages

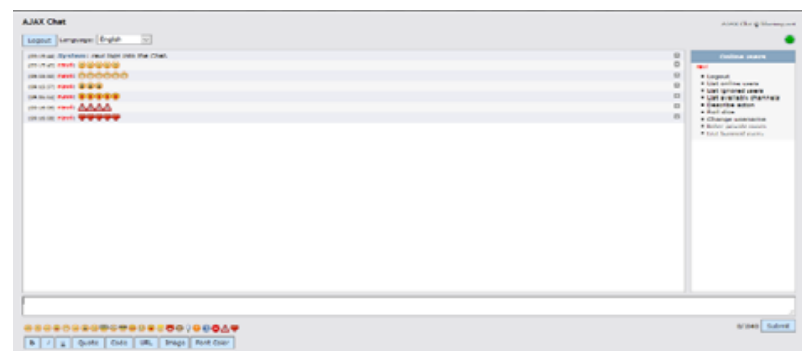

Snapshot 7: Ajax Chat Layout 


\section{CONCLUSION}

While developing this application a conscious effort has been made to create and develop a software package, making use of available tools, techniques and resources that would generate a proper system for family social networking.

While designing the application, an eye has been kept on making it as user-friendly. This is a web-based application[18,19], where members log on to the system in order to visit their family page. Initially, the group is started by one member of the family, who is given ownership status. He/she is given the privilege of adding anyone he/she wants to. Therefore it creates a bonding among relatives and helps them stay connected.

There are some of the areas of improvement which could not be implemented due to time constraints. One such feature was genealogy studies which is the study of family diseases.

\section{FUTURE WORK}

At present the website is locally hosted, in future it can be hosted in cloud so that everyone can access the application over the internet. The application also includes disease and blood group sections in the profile, in future it can be used to create a powerful genealogy[20,21] database which helps in early diagnosis of genetically acquired diseases. However this has been left for further enhancement of this project.

- In future a search option may be included so that the users can easily search their family members by their name. This would further enrich the user experience of the application.

- The web application should also be able to connect with Facebook in order to fetch basic information from the Facebook profile.The user shall skip registration and shall be able to login using their Gmail or Facebook credentials.

\section{REFERENCES}

[1] Ancestry24

"https://www.revolvy.com/main/index.php?s=Ancestry24\&ite m_type=topic"

[2] Six Degrees Social Engine, "http://sixdegrees.com"

[3] BlackPlane,"https://en.wikipedia.org/wiki/BlackPlanet”

[4] Daniel Nations, WhatIs

Facebook?,”https://www.lifewire.com/what-is-facebook3486391"

[5] Linkedin, "http://www.wikiwand.com/en/LinkedIn"

[6] Twitter, "https://en.wikipedia.org/wiki/Twitter"

[7] Dorsey, Jack,just setting up my twttr,"https://twitter.com/jack/status/20?lang=en"

[8] "Google+", "https://en.wikipedia.org/wiki"

[9] Ara wagoner ,What is Google+ and why should I use it, "https://www.androidcentral.com/what-google-and-whyshould-i-use-it"

[10] TAYLOR CASTI,"9 Social Networks for Organized families", http://mashable.com/2013/06/20/social-networksfamilies

[11] How to Create a Social Network for Family, "https://www.oxhow.com/create-social-network-for-family"

[12] Goodman, Wes. GIC and Silver Lake Invest in U.S.GenealogyCompanyAncestry, "https://www.bloomberg.com/news/articles/20160402/gicand-silver-lake-invest-in-u-s-genealogy-company-ancestry"

[13] ApacheDocumentation "https://httpd.apache.org/docs/2.4"

[14] Nixon,Robin "Learning PHP,Mysql,Javascript “4 $4^{\text {th }}$ edition 2014, O’Reilly media Publishing, Inc.pp.233-263

[15] PHP MyAdmin "https://www.phpmyadmin.net/docs"

[16] Documentation for PHP http://php.net/docs.php

[17] Steps to Create a Website for Beginner's, "http://dotzweb.com/steps-to-create-a-website-development/"

[18] PrivateSocialNetworking," http://www.familycms.com"

[19] MySQLDocumentation, "https://dev.mysql.com"

[20] Family crossing,"https://www.familycrossings.com/index.html"

[21] Genealogy:ResearchingYourFamily Tree,https://www.futurelearn.com/courses/genealogy 